\title{
LA LIBERTAD DE CREENCIAS EN LA CONSTITUCIÓN JAPONESA
}

\author{
LUIS PEDRIZA
}


SUMARIO

I. INTRODUCCIÓN. II. LA LIBERTAD DE CREENCIAS EN EL SISTEMA CONSTITUCIONAL MEIJI. 1. El art. 28 de la Constitución Meiji. 2. El Sintoísmo de Estado. 3. La derrota de Japón y la nueva Constitución japonesa. III. LA LIBERTAD DE CREENCIAS EN LA CONSTITUCIÓN JAPONESA. 1. La regulación constitucional de la libertad de creencias. 2. El contenido de la libertad de creencias. IV. A MODO DE CONCLUSIÓN. 


\title{
LA LIBERTAD DE CREENCIAS EN LA CONSTITUCIÓN JAPONESA
}

\author{
LUIS PEDRIZA \\ Profesor de Derecho Constitucional y Comparado \\ Universidad de Osaka
}

\section{INTRODUCCIÓN}

$\mathrm{Al}$ igual que la mayoría de las constituciones democráticas contemporáneas, la japonesa de 1947 garantiza la libertad de creencias, encabezando el catálogo de derechos fundamentales de su parte dogmática. Japón es un Estado que protege esta radical libertad del espíritu de la manera más amplia posible, en consonancia con los estándares internacionales en la materia ${ }^{1}$.

Si bien es el japonés un sistema jurídico que, por razones geográficas, culturales y, cómo no, lingüísticas, resulta en general extraño para el estudioso occidental, lo cierto es que, al menos en espíritu, no debiera resultarnos tan alejado. Aún así, el estudio del Derecho japonés suele permanecer desconocido para gran parte de nuestra academia, siendo pues una «asignatura pendiente» para la investigación patria ${ }^{2}$.

1 Japón firmó el Pacto Internacional de Derechos Civiles y Políticos el 30 de mayo de 1978, ratificándolo el 21 de julio de 1979.

${ }^{2}$ En lengua española podemos destacar el reciente ensayo de Juan Francisco LÓPEZ AGUILAR, Japón constitución, parlamentarismo, Poder Judicial. Una mirada española, Congreso de los Diputados, Madrid, 2009. Aunque escueto, resulta un interesante portal introductorio al sistema constitucional japonés. Como monografía, el excelente trabajo sobre la Casa Imperial Japonesa de Salvador, RODRÍGUEZ ARTACHO, La monarquía japonesa, Centro de Estudios Constitucionales, Madrid, 2001. También la edición bilingüe del Código Civil Japonés contiene un interesante y completo estudio sobre la recepción del derecho occidental en Japón: BARBERÁN, Francisco y DOMINGO, Rafael, Código Civil Japonés, Thomson/Aranzadi, Cizur Menor, 2006, pp. 25-56. 
El objetivo del presente trabajo es presentar al lector hispanohablante un tema nuclear dentro del constitucionalismo japonés: el estudio de la libertad de creencias (en sus dos vertientes ideológica y religiosa). A diferencia de lo que ocurre los países de nuestro entorno, Japón no cuenta para el estudio de esta materia con una disciplina científica como la del Derecho eclesiástico de Estado. La libertad de creencias es pues coto privado para los iusconstitucionalistas nipones.

En el desempeño de nuestra labor, iniciaremos el trabajo con una breve reseña histórica para vislumbrar la evolución de la garantía y defensa de la libertad de creencias en el casi siglo y medio de constitucionalismo japonés. A continuación realizaremos un estudio del contenido de dicha libertad dentro de la Constitución, cuya garantía aparece sistematizada a través de varios artículos dentro de la Norma Fundamental. Haremos referencia finalmente al principio de separación religión-estado, garantía de la libertad de creencias en su vertiente religiosa y de importancia capital en la estructura constitucional japonés.

\section{LA LIBERTAD DE CREENCIAS EN EL SISTEMA CONSTITUCIONAL MEIJI}

\section{El art. 28 de la Constitución Meiji}

La historia del constitucionalismo japonés arranca el 11 de febrero de 1889 con el nacimiento de la Constitución Imperial, popularmente se conocida como Constitución Meiji ${ }^{3}$. Este texto estuvo en vigor por un periodo de de casi sesenta años, hasta la derrota del Imperio japonés frente a las Fuerzas Aliadas en $1945^{4}$. Con la Constitución Meiji finaliza un largo proceso constituyente (la redacción del texto propiamente dicha duró casi tres años) iniciado en 1868 con

3 Por el nombre del emperador bajo cuyo reinado vio la luz. Meiji es el nombre que recibió el Emperador Mutsuhito (1852-1912). Los japoneses suelen referirse a su Emperador con el nombre de su reinado más que por su nombre de pila. Según lo establecido por la Ley de Eras de 1979, en sus artículos primero y segundo, la denominación de cada era o gengô 元号 en japonés, se determina por decreto del Gabinete, con ocasión de la entronización del nuevo Emperador. Actualmente nos encontramos en la era de Heisei (平成).

${ }^{4}$ La Constitución Meiji tomó como modelo el de la prusiana de 1850. Para un completo estudio histórico jurídico sobre la Constitución Meiji el mejor estudio sin lugar a dudas es ÔISHI, M., Nibon Kenpôshi (Dainihan) 日本憲法史（第2版） (Historia del constitucionalismo japonés. 2. ${ }^{a}$ ed.), Yûhikaku, Tokio, 2005. 
la Restauración Meiji (meiji ishin 明治維新), proceso revolucionario que tanto sociopolítica, cultural y científicamente logrará modernizar Japón's

Se trataba de una constitución otorgada de corta extensión de (76 artículos), cuya parte dogmática establecía una carta de derechos y libertades para los súbditos (shinmin 臣民). Los derechos aquí reconocidos tenían la naturaleza de prerrogativas o «favores» (onkei 恩恵) concedidos por el Emperador, soberano de la Nación y fuente del poder constituyente ${ }^{6}$. Del sistema de protección de derechos bajo el sistema constitucional Meiji pueden predicarse dos características:

1. El contenido de los derechos debía ser desarrollado por ley. Sin embargo, este principio de «reserva legal» (bôritsu no ryûhô 法律の留保) fue empleado más para restringir derechos que para desarrollarlos.

2. No existía ningún procedimiento de control de constitucionalidad encaminado a proteger en vía judicial los derechos y libertades reconocidos por la Constitución; pues la Constitución Meiji carecía de supremacía tanto formal como material dentro del ordenamiento.

Con respecto a la libertad de creencias, en 1868, al comienzo de la Restauración Meiji, el gobierno japonés se mostraba partidario de continuar con aquella política de prohibición del cristianismo que el antiguo régimen feudal de los Tokugawa, había venido desarrollando desde 1614. Sin embargo, presionado por las potencias occidentales por un lado y tras veinte años aprendiendo constitucionalismo moderno por el otro, el constituyente japonés decidió incluir la libertad religiosa (shinkyô no jiŷ人 信教の自由) en el art. 28 de la Constitución en los siguientes términos:

Los súbditos japoneses disfrutan de libertad de religión, siempre que ésta no contravenga el orden público ni suponga un menoscabo al cumplimiento de los deberes propios de los súbditos.

Sobre este derecho de la libertad religiosa concurrían por supuesto las dos características ya mencionadas. Sin embargo para comprender mejor el ámbito

5 Desde principios del s. XVII, Japón había permanecido anclado en un sistema feudal y aislado casi por completo del extranjero por más de doscientos cincuenta años. La historiografía hace referencia a este periodo como «etapa del país encadenado» (sakoku jidai 鎖国時代).

${ }^{6}$ La Constitución titulaba su capítulo segundo «De los derechos y deberes de los súbditos». Sobre la naturaleza de los derechos reconocidos por la Constitución Meiji, vid. NAKANO, T., NAKAMURA, M., TAKAHASHI, K. y TAKAMI, K., Kenpô I 憲法I (Derecho constitucional I), Yûhikaku, Tokio, 2006, p. 206. 
real de la garantía de esta libertad, hay relacionarla con un fenómeno sociológico, jurídico y político que aconteció durante todo su periodo de vigencia: el «Sintoísmo de Estado». Esta «variedad» de sintoísmo también denominado «de santuario» (jinja shintô) se imbricaba de tal manera en la estructura del Estado japonés hasta el punto constituir sus cimientos ontológicos.

\section{El Sintoísmo de Estado ${ }^{7}$}

En líneas generales, podemos tratar de definir sintoísmo como la religión animista nativa de Japón cuyo culto se basa en la adoración de unos espíritus o númenes de la naturaleza denominados kami (神). En primer término, el culto sintoísta tiene una naturaleza local y familiar. Sin embargo al mismo tiempo, existen unos kami de «carácter nacional», protectores de la nación japonesa, a los que se rinde culto público. Este panteón de kami «nacionales» está encabezado por Amaterasu, diosa del Sol, que es a su vez el antepasado directo de la Casa Imperial $^{8}$.

Históricamente, este sintoísmo «nacional» se desarrolló a partir de los siglos VII y VIII sirviendo de motor espiritual para la unificación del país bajo el poder de la Corte Imperial primero en Nara y luego en Kioto. El núcleo de su doctrina se encuentra recogido en dos crónicas, el Kojiki escrita en 712 y el Nihonshoki en 720, redactadas para legitimar el poder político del Emperador. Sus relatos nos cuentan que el primer Emperador de Japón fue el mítico Jinmu,

7 Sobre Sintoísmo de Estado vid. KAMIMURA, S., Kokka-Shintô 国家神道 (El Sintoísmo de Estado), Iwanami, Tokio, 1970, y más recientemente SAKAMOTO, K., Kokka-Shintô keiseika-

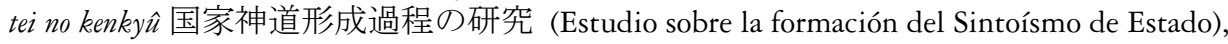
Iwanami, Tokio, 1994. Ambos son estudios clásicos en la materia. En lengua inglesa destacamos HARDACRE, H., Shinto and the State, 1868-1988, University Press, Princeton, 1988. También de la misma autora, «Creating state shintô: the Great Promulgation Campaign and the new Religion» en Journal of Japanese Studies, 12.1, 1986 pp. 29-63. Sobre sintoísmo en general ASTON, William G Shinto - the way of the gods, Collected Works of William George Aston, Oxford University Press, 1997, reimpresión del original publicado en Londres en 1905. La fue escrita décadas antes de la entrada de Japón en la Guerra del Pacífico pero se trata de un clásico de obligada referencia redactado por uno de los más afamados japonólogos occidentales de todos los tiempos.

${ }^{8}$ El vocablo japonés para designar al Emperador, tennô (天皇), literalmente significa «soberano del Cielo». Es precisamente en el siglo VII cuando se empieza a utilizar esta denominación, coincidiendo con un proceso de «espiritualización» del poder de Emperador que hasta entonces solía denominarse ookimi (大王), esto es el rex regum dentro de los poderes locales que intentan unificar el país. 
entronizado en el 660 a. C., y cuya estirpe enlaza directamente con la Casa Imperial $^{9}$.

Pues bien, en el siglo XIX la Restauración Meiji tendrá como objetivo primordial devolver el poder político al Emperador, cuya figura tras siglos de gobiernos castrenses, había quedado relegada a funciones meramente ceremoniales. Aunque su importancia como símbolo de unidad de la nación japonesa había permanecido inalterada durante todo ese tiempo. El ideal político perseguido por el movimiento de la Restauración no era otro que el de la unificación del poder político y el poder religioso (saisei-icchi 祭政一致) en la figura del Emperador. La Constitución Meiji por su parte, se encargará de institucionalizar dicho culto conformando un modelo de Estado denominado kokutai (国体), que podríamos catalogar como una «teocracia constitucional», centrada en la figura del Emperador, considerado un auténtico dios viviente (arabitogami 在人神). Así, la «constitucionalización» de sintoísmo nacional debía servir a la postre para garantizar la unidad espiritual de la nación japonesa ${ }^{10}$.

Bajo el paraguas del Sintoísmo de Estado, se creó una auténtica red nacional de santuarios y sacerdotes de carácter oficial, para garantizar el culto público al Emperador. Estos santuarios sintoístas (jinja 神社) se configuraron como corpo-

9 Como culto religioso, el sintoísmo ha sido siempre muy ecléctico, recibiendo a lo largo de su historia influencias varias del confucionismo, taoísmo y, por supuesto, budismo. Con esta última religión, se produjo a finales del VIII un curioso fenómeno de simbiosis denominado shinbutsushûgôo(神仏習合), literalmente «unión de los dioses con los budas».

${ }^{10}$ Como estudios sobre el concepto de Kokutai, dentro del ingente número de obras que pueden encontrarse en legua japonesa, por su influencia, debemos hacer referencia a los trabajos del afamado politólogo MARUYAMA, Masao. Destacamos entre todas Nibon no shisô 日本の思 想 (El pensamiento Japonés), Iwanami, Tokio, 1961 y Gensaiseiji no shisô to kôdô 現代政治の思 想と行動 (Pensamiento y comportamiento políticos actuales), Miraisha, Tokio, 1956. De esta obra existe una traducción al inglés: Thought and Behaviour in Modern Japanese Politics, Oxford University Press, 1969, editada por MORRIS, I. En lengua inglesa podemos destacar KITAGAWA, M. «The Japanese Kokutai (National Community) History and Myth,» en History of Religions, 13.3, 1974, pp. 209-226; BECKMANN, G. M. The Making of Meiji Constitution. The Oligarcs and the Constitutional Developement of Japan (1868-1891), University of Kansas Press, 1957; DAIKICHI, I. The Culture of the Meiji Period, Princeton University Press, Princeton, 1970. Una traducción al inglés del famoso texto Kokutai no Hongi (国体の本義), publicado en 1937 por el Ministerio de Educación nipón como exposición oficial de los principios informadores del concepto, la encontramos en HALL, R. K. (ed.) Kokutai no Hongi. Cardinal Principles of The National Essence of Japan Harvard University Press, 1949. Además en lengua castellana, los meritorios trabajos de LANZACO, F. Introducción a la cultura japonesa -pensamiento y religión, Universidad de Valladolid, Valladolid, 2000 y de GONZÁLEZ VALLÉS, J. Historia de la Filosofía japonesa, Tecnos, Madrid, 2000 tratan también este concepto. 
raciones de derecho público y sus sacerdotes tenían el estatus de funcionarios del Estado.

En este punto, debe asaltarnos una duda importante: ¿cómo se conjugaba la existencia de una religión de Estado con la garantía de la libertad religiosa? La respuesta que daba el gobierno japonés de entonces era simple: Sintoísmo de Estado no era una religión stricto sensu ${ }^{11}$. Esto es, la libertad religiosa reconocida constitucionalmente se circunscribía al culto «privado», y siempre dentro de los límites del cumplimiento de los deberes propios de los súbditos ${ }^{12}$. Y el primero de estos deberes no era otro que el culto al Emperador.

Religión o no, la realidad es que el Sintoísmo de Estado funcionó como un sistema de creencias de carácter oficial con el consiguiente menoscabo del derecho libertad religiosa de los ciudadanos. De hecho, a partir de la década de los treinta, el hasta entonces formalista culto al Emperador (tennô sûbai 天皇崇拝) se impregnará de una ideología de carácter totalitario y racista que a la postre servirá de espoleta para el expansionismo militarista del Japón.

\section{La derrota de Japón y la nueva Constitución japonesa}

Tras la Declaración de Postdam (1945), Japón reconoce su derrota frente a las fuerzas Aliadas y comienza un periodo de ocupación militar del país que se prolongará hasta 1952. Una de las exigencias de la dicha declaración era la «consolidación la democracia y la protección de los derechos fundamentales». Esto es, los Aliados instaban al gobierno para que removiera todos aquellos obstáculos que imposibilitaban la completa protección del derecho, entre otros, a la libertad de creencias. Conscientes además de la influencia que el Sintoísmo de Estado había ejercido en las ambiciones expansionistas del Imperio japonés, el 15 de diciembre de 1945, el mando de las Fuerzas Aliadas popularmente conocido como GHQ (General Headquarters), entregará al gobierno un memorándum «sobre sintoísmo», en el que se instaba al desmantelamiento del edificio del Sintoísmo de Estado ${ }^{13}$. Es con la desaparición, al menos formalmente, del apa-

${ }^{11}$ La opinión del gobierno acerca de la naturaleza del sintoísmo estatal era clara y sencillamente «jinja wa shûkkyôni arazu» (神社は宗教に非ず), esto es, «el sintoísmo de santuario no es una religión». ÔISHI, M., Kenpô kôgi II 憲法講義 II (Lecciones de Derecho constitucional), Yûhikaku, Tokio, 2007, p.120.

12 Así lo indicaba claramente Itô HIROBUMI, unos de los «padres» de la constitución Meiji, en su obra «Comentarios a la Constitución». Vid. ITÔ, H. (edición de MIYAZAWA, T.), Kenpố gige 憲法義解 (Comentarios a la Constitución), Iwanami, Tokio, 1997, p. 60.

13 Se trata de la SCAPIN (Supreme Commander for the Allied Powers Instruction Note) -448 , for «Abolition of governmental sponsorship, support, perpetuation, control and dissemination 
rato del Sintoísmo de Estado, cuando van a concurrir unas circunstancias óptimas para la completa garantía constitucional de la libertad creencias.

\section{LA LIBERTAD DE CREENCIAS EN LA CONSTITUCIÓN JAPONESA}

\section{La regulación constitucional de la libertad de creencias}

La Constitución japonesa sistematiza la protección de la libertad de creencias a través de varios artículos:

En primer lugar el art. 14, párrafo primero, al proclamar el principio de igualdad ante la ley y el de interdicción de toda discriminación por razón, entre otras, de las creencias:

Todos los ciudadanos son iguales ante la ley y no existirá discriminación politica, económica o social por razones de raza, credo, sexo, condición social o linaje.

En segundo lugar el art. 19, que garantiza la libertad de conciencia y pensamiento:

No se violará la libertad de pensamiento y de conciencia.

En tercer lugar el art. 20, que reconoce la libertad religiosa y el principio de separación religión-estado:

1. Se garantiza la libertad religiosa de los individuos. Ninguna organización religiosa recibirá privilegios del Estado ni podrá ejercer cualquier tipo de potestad política.

2. Nadie estará obligado a tomar parte en actos, celebraciones, ritos o prácticas religiosas de cualquier indole.

3. Ni el Estado ni sus instituciones podrán impartir educación religiosa ni participar en cualquier otra actividad religiosa.

Finalmente, el art. 89, que concreta el principio de separación religiónestado en el ámbito de las finanzas públicas.

of State Shinto». Para más información en lengua inglesa vid. GOODMAN, C., The rule of Law in Japan: a comparative analysis, Kluwer Law International, La Haya, 2003, pp. 76-78. Un ejemplo paradigmático de esta «desacralización» de la política japonesa lo encontramos en la renuncia pública de su estatus divino que el emperador Hirohito (1926-1989) realizó por retransmisión radiofónica el 1 de enero de 1946. 
Los recursos públicos no serán utilizados para uso, beneficio o mantenimiento de instituciones o asociaciones religiosas, o para empresas de caridad, educacionales o bumanitarias, que no estén bajo el control de la autoridad pública.

Además de los citados artículos, también debemos referirnos a otras dos disposiciones que guardan relación directa con la libertad de creencias.

El art. 21, párrafo primero, que garantiza en entre otras la libertad de expresión, reunión y asociación:

Se garantiza la libertad de reunión y asociación, de palabra y de prensa, como también toda otra forma de expresión.

El art. 13 que dispone:

Todos los nacionales serán respetados como individuos. Su derecho a la vida, a la libertad y a la búsqueda de la felicidad, será, en tanto que no interfiera con el bienestar público, el objetivo supremo de la legislación y de los demás actos de gobierno.

Este artículo, al que gran parte de la doctrina reconoce como el «derecho a la búsqueda de la felicidad» ${ }^{14}$, funciona en el plano teórico como cláusula general de garantía constitucional de todos los derechos fundamentales. El art. 13 es la «cláusula general de derechos fundamentales» (bôkatsutekijinken kitei 包括的 人権規定) de la Constitución japonesa» ${ }^{15}$. También desde una perspectiva práctica, el art. 13 cumple una función capital en la hermenéutica constitucional pues es utilizado por doctrina y jurisprudencia como soporte normativo para todos aquellos derechos y libertades que el constituyente no recogió expresamente en la parte dogmática al tiempo de su redacción pero que, con el paso de los años, su garantía deviene necesaria ${ }^{16}$. Con respecto a la libertad de creencias, a través del art. 13 se ha fundamentado el denominado «derecho de autodetermi-

${ }^{14}$ La redacción del artículo recibe clara influencia de la Declaración de independencia de los Estados Unidos. Vid. TAKAI, H., «Kôfukutsuikyûken» 幸福追求権 (El derecho a la búsqueda de la felicidad). En TAKAHASHI, K. (coord.), Kenpôn no sôten 憲法の争点 (Puntos problemáticos de Derecho constitucional), Yûhikaku, Tokio, 1999, p. 70.

15 Ibídem p. 71.

${ }^{16}$ Sobre el derecho a la búsqueda de la felicidad vid. TANEYA, H. «Seimei, jiyû oyobi kôfukutsuikyûken» 生命自由及び幸福の追求 (El derecho a la vida, la libertad y la búsqueda de la felicidad) En ASHIBE, N. (coord.), Kenpô II. Jinken I 憲法II 人権I (Derecho Constitucional II; Derechos humanos), Yûhikaku, Tokio, 1978, pp. 130 y ss.; MUNESUE, Y. «Kôfukutsuikyûken ni tsuite» 幸福追求権いついて (Sobre derecho a la búsqueda de la felicidad) en Jurist, n. ${ }^{\circ}$ 1089, 1996, pp. 179 y ss.; TONAMI, K. «Kôfukutsuikyûken no kôzô» 幸福追求権 の構造 (La estructura del derecho a la búsqueda de la felicidad) en Kôbôkenkyûu, n. ${ }^{\circ}$ 58, 1996, pp. 1 y ss. 
nación» (jikokettei ken 自己決定権), que incluiría por supuesto la autodeterminación por causas ideológicas y de creencias $^{17}$.

\section{El contenido de la libertad de creencias}

El núcleo de la libertad de creencias viene garantizado en los arts. 19 y 20, siendo el primero la garantía general de libertad ideológica y de pensamiento, y el segundo la especificación de esa misma libertad en su vertiente religiosa. En términos taxonómicos, estaríamos ante el género y la especie respectivamente de la libertad de creencias. Siguiendo la propedéutica empleada por la doctrina japonesa, analizaremos ambos artículos de manera separada.

\subsection{El artículo 19}

La norma emplea los términos «conciencia» (ryôshin 良心) y «pensamiento» (sbisô思想), por lo que cabe preguntarse si el legislador está regulando dos cosas distintas dentro de esta libertad. Algunos autores distinguen entre conciencia como el sentimiento moral o facultad de distinción entre el bien y el mal, y pensamiento como la facultad de raciocinio ${ }^{18}$. Independientemente de lo afinado de esta distinción, lo cierto su interés jurídico es escaso, ya que lo que el constituyente trata es de proteger la interioridad del individuo de la manera más amplia posible, y es por ello que la mayoría de la doctrina ve innecesario hacer distinciones entre conciencia y pensamiento ${ }^{19}$.

Lo que sí ha sido objeto de debate tanto doctrinal como jurisprudencial ha sido el determinar el grado de amplitud con el que la Norma Fundamental

17 Sobre este derecho de autodeterminación, ARIKAWA, T., «Jikoketteiken» 自己決定権 (El derecho de autodeterminación). En TAKAHASHI, K. (coord.), Kenpô no sôten 憲法の争点 (Problemática de Derecho constitucional), Yûhikaku, Tokio, 1999, pp. 74 y ss.; K, SATÔ, K., «Nihonkokukenpô to jikoketteiken»日本国憲法と自己決定権 (La constitución japonesa y el derecho de autodeterminación) en Hôgakukyôshitsu, n. ${ }^{\circ}$ 98, 1988, pp. 6 y ss.; TONAMI, K., 《Jikokketeiken no igi to han'i» 自己決定権の意義と範囲 (El derecho de autodeterminación: significado y alcance) en Hôgakukyôshitsu, n. ${ }^{\circ} 158,1993$, pp. 36 y ss.

18 SATÔ K., Kenpô (daisanban) 憲法（第3版） (Derecho constitucional 3. ${ }^{a}$ ed.), Seirinshôin, Tokio, 1995, p. 484. En opinión de este autor, el art. 19 tiene una proyección ad intra, (y en ese sentido su garantía sería ilimitada). Esta libertad se proyectaría ad extra a través del resto de libertades garantizadas, tales como la de religión, expresión, reunión, cátedra, etc.

19 Así, ASHIBE, N., Kenpô (daisanban) 憲法（第3版） (Derecho Constitucional 3. ${ }^{a}$ ed.), Iwanami, Tokio, 2005, p. 140. También UCHINO, M., Kenpôkaishaku no sôten (daiyonban) 憲法 解釈の争点 (第 4 版) (Problemática de la interpretación constitucional 4. ${ }^{\mathrm{a}}$ ed.), Nihonhyôronsha, Tokio, 2005, pp. 61-62. 
garantiza esta libertad de conciencia-pensamiento. En primer lugar tenemos una posición que se decanta por una interpretación restringida (genteisetsu 限定説) ${ }^{20}$. Así, el binomio conciencia-pensamiento haría referencia a aquellos contenidos que conforman el núcleo de la propia individualidad, por ejemplo, las convicciones morales, las ideas políticas, las cosmovisiones y los credos religiosos, Quedan pues excluidas las meras opiniones, puntos de vista, gustos, inclinaciones, etc. En segundo lugar existe una interpretación amplia (kôgisetsu 広義説) de la norma, que reconoce la protección de cualquier tipo de actividad espiritual e intelectual del individuo ${ }^{21}$.

El origen de este debate se inició con una famosa sentencia de la Corte Suprema de 4 de julio de $1956^{22}$. Se trataba de un caso en el que un candidato a parlamentario había sido condenado a publicar en prensa una disculpa pública (shazai kôkoku 謝罪広告) por difamación contra otro candidato ${ }^{23}$. Pues bien, discurría el Alto Tribunal acerca de si el forzar a alguien a disculparse públicamente (evidentemente cuando no existe en el obligado ninguna intención de arrepentimiento) podía considerarse una violación del art. 19. La sentencia disponía en primer lugar que el objeto de esta disculpa pública no era otro que reconocer la mala fe de las difamaciones y, en segundo lugar, que en la sociedad japonesa el hecho de disculparse formalmente puede considerarse una mera norma de cortesía. En conclusión, la citada condena no vulneraba la garantía del artículo 19.

En parte por falta de acuerdo sobre el contenido «positivo» del art. 19, la mayor parte de la doctrina opta por explicar el contenido de este artículo 19 desde una perspectiva «negativa» ${ }^{24}$. Esto es, sin referirse directamente al signi-

20 SATÔ, K., Kenpô (daisanban), op.cit., p. 485.

${ }^{21}$ Así ASHIBE, N., Kenpô (daisanban) op.cit. p. 141. También HIGUCHI, Y. Chûkai hôritsugaku zenshâ. Kenpô I 注解法律学全集、憲法I (Comentarios legislativos. Derecho Constitucional I), Seirinshoin, Tokio, 1994, pp. 376-377.

${ }^{22}$ Jurisprudencia de la Corte Suprema 31.7.4, repertorio de jurisprudencia civil, vol. 10, n. ${ }^{\circ} 7$, pp. 785. Un comentario a esta sentencia lo podemos encontrar en SERIZAKI, H. «Ryôshin no jiyû to shazaikôkoku no kyôsei» 良心の自由と謝罪広告の強制 (La libertad de conciencia y la imposición de disculpas públicas). En TAKAHASHI, K. (coord.), Kenpô hanrei hyakusen (daigohan) 憲法判例百選（第5版） (Cien sentencias constitucionales seleccionadas, 5. ${ }^{a}$ ed.), Yûhikaku, Tokio, 2007, pp. 76-77.

${ }^{23}$ Esta disculpa pública tiene soporte legal en virtud del artículo 723 del Código civil, que dispone: "Respecto de quien bubiese lesionado la fama o el honor de otra persona, el Tribunal podrá ordenar, a instancia del perjudicado, en lugar de la correspondiente indemnización de o además de ella, la adopción de las medidas necesarias para el pleno restablecimiento de la fama o el honor del afectado».

${ }^{24}$ NEMORI, K. «Shisô, ryôshin no jiyû»思想良心の自由 (La libertad de concienciapensamiento). En TAKAHASHI, K. (coord.), Kenpô no sôten 憲法の争点 (Problemática de Derecho constitucional), Yûhikaku, 1999, p. 86. 
ficado del binomio conciencia-pensamiento, se prefiere prestar atención a la expresión «no se violará» y deducir de ellas tres concretas interdicciones dirigidas a los poderes públicos: 1. Prohibición de adoctrinamiento ideológico. 2. Prohibición de cualquier trato discriminatorio por razón de creencias. 3. Prohibición de forzar a un individuo a declarar acerca de las propias convicciones.

\subsection{El artículo 20}

Esta norma garantiza la libertad religiosa añadiendo como garantía de la misma el principio de separación religión-estado ${ }^{25}$. Así pues para analizar el contenido del precepto debemos atenernos a este doble contenido. Sin embargo, antes de iniciar nuestro análisis será interesante responder cierta pregunta: ¿qué debe entenderse en Derecho japonés por «religión» ${ }^{26}$ ?

Es bien conocido el hecho de que ya desde tiempos remotos los japoneses han gozado de un sentido religioso muy amplio. Desde una perspectiva religiosa, es la japonesa una sociedad eminentemente sincrética. Pues bien, todo este sincretismo y laxitud ha impregnado también su cultura jurídica, con interpretaciones que sin duda llaman la atención a los ojos de un occidental. Ejemplo paradigmático de todo ello podemos encontrarlo en una definición que sobre el término «religión» realizó la Corte de apelación de Nagoya en una sentencia de 1972 sobre la presunta inconstitucionalidad de una ceremonia sintoísta para la purificación del terreno (jichinsai 地鎮祭) promovida por el ayuntamiento de la ciudad de Tsu, en la prefectura de Mie. Esta es la definición propuesta por el tribunal $^{27}$ :

En nuestro sistema constitucional, podemos denominar religión a ese sentimiento de veneración y creencia en la existencia de esencias sobrenaturales y sobrebumanas, llámese el Ser Absoluto, el Creador, el Ser Supremo, y en especial en el culto a los dioses, a los budas $y$ los espiritus.

A pesar del escaso rigor académico de la definición, lo cierto es que hizo fortuna en la doctrina científica llegando a ser sistemáticamente utilizada en la

${ }^{25}$ En japonés seikyôbunri-no-gensoku (政教分離の原則). Aunque algunos autores suelen traducirlo como «principio de laicidad», teniendo en cuenta la influencia norteamericana en la redacción del artículo nos hemos decantado por una traducción literal del término. Por razones de economía de lenguaje, nos referiremos a este principio como «de separación».

${ }^{26}$ El vocablo utilizado en japonés para significar «religión», shûkŷ (宗教), es un neologismo de mediados XIX empleado para traducir el término latino religio.

27 Sentencia del Tribunal Superior de Nagoya 46.5.15, repertorio de jurisprudencia administrativa, vol. 22, n. $^{\circ} 5$, p. 680. 
mayoría de manuales de Derecho constitucional al uso. Así, por ejemplo, Makoto ÔISHI define religión como «sentimiento de confrontación hacia un ser absoluto de naturaleza trascendente» ${ }^{28}$. Los términos empleados son desde luego más sencillos que aquellos utilizados por el tribunal del Nagoya, pero no cabe duda de que ambas definiciones tienen un denominador común: indefinición y sincretismo. Por otro lado, Kôji SATÔ, opina que la Constitución japonesa utiliza el término «religión» en dos sentidos: uno amplio, con relación a la libertad religiosa, y que coincidiría con las definiciones propuestas, y otro restringido, con relación al principio de separación y que haría referencia a las diferentes confesiones religiosas ${ }^{29}$. Está última postura cuenta con amplio respaldo académico.

\subsubsection{Contenido de la libertad religiosa}

Llama la atención lo sucinto de la expresión utilizada por el párrafo primero del artículo 20: «se garantiza la libertad religiosa de los individuos». Pareciera como si el texto constitucional diera por sentado la existencia de un consenso previo sobre el significado de dicha libertad ${ }^{30}$. Sin embargo esto no es así, y han tenido que ser la doctrina y la jurisprudencia las que, a posteriori, hayan delimitado el contenido de la libertad religiosa. La gran mayoría de los autores señalan tres contenidos concretos:

1. Libertad de credo (shinkô no jizŷu信仰の自由): Esta libertad sería la «especificicación religiosa» de la libertad de conciencia-pensamiento del artículo 19. Se trata pues de la proyección ad intra de la libertad religiosa. Al igual que con el artículo 19, el contenido de dicha libertad puede analizarse de manera «negativa», derivándose de la garantía de esta libertad tres prohibiciones dirigidas a los poderes públicos: prohibición de adoctrinamiento religioso, de trato discriminatorio y de forzar a un individuo a declarar las propias creencias religiosas. Ahora bien, desde una perspectiva «positiva», suele señalarse como contenido de esta libertad de credo, la libertad para abrazar o no un credo religioso y la libertad de cambiar o abandonar el que se tenga.

2. Libertad de actuación religiosa (shûkyôteki kôi no jiŷu宗教的行為の自由): Es decir libertad de participar en actos y ceremonias de carácter religioso y la

28 ÔISHI, M. Kenpô to shûkyô seido 憲法と宗教制度 (Constitución y sistema religioso), Yûhikaku, Tokio, 1997, p. 236.

29 SATÔ, K., Kenpô (daisanban), op.cit. pp. 500 y ss.

30 No existe en Derecho japonés una norma como la Ley Orgánica de Libertad Religiosa española (Ley 7/1980), que delimite de manera normativa el contenido de la libertad religiosa. 
libertad de transmitir y propagar las propias creencias. Esta libertad de actuación religiosa estaría también protegida por la garantía de la libertad de expresión y de reunión que recoge el artículo 21 del texto constitucional.

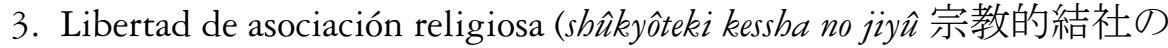
自由): Es decir libertad para fundar entidades religiosas y de adscribirse o abandonar una existente. También este contenido quedaría garantizado por la libertad de asociación reconocida por el citado artículo 21.

Los contenidos segundo y tercero constituyen la proyección ad extra de la libertad religiosa, y algunos autores se refieren a ellos conjuntamente como «libertad de culto» (reibai no jiŷu礼洋の自由) $)^{31}$.

Finalmente, debemos referiremos a otros dos contenidos o libertades cuya inclusión o no en la garantía del art. 20 ha sido ocasionado de controversia en el debate doctrinal.

En primer lugar el derecho a la «individualidad religiosa» (shûkyôteki jinkakuken 宗教的人格権), que como algún autor señala, se trataría del derecho a vivir la fe personal en un ambiente de tranquilidad y sosiego religioso ${ }^{32}$. Este derecho saltó por primera vez a la palestra a principios de la década de los 80 , a través de una polémica causa en la que la viuda de un oficial de las Fuerzas de Autodefensa reclamaba al Estado una indemnización por daños morales, ya que su difunto marido había sido objeto de un homenaje sintoísta por parte de una asociación de miembros de esta Fuerzas de Autodefensa, a pesar de su férrea oposición (tanto ella como su esposo eran cristianos). La parte demandante argumentaba su derecho a vivir el duelo conforme a su fe religiosa sin ser molestada.

Pues bien, aunque los tribunales de primera y segunda instancia fallaron a favor de la viuda, la Corte Suprema en su sentencia de 1 de julio de 1988 lo hizo en sentido contrario ${ }^{33}$. En primer lugar opinaba el Alto Tribunal que la asociación de miembros de las Fuerzas de Autodefensa que había encargado el homenaje no tenía naturaleza pública y que por lo tanto su actividad no quedaba limitada por el principio de separación. Además el Supremo entendió que el referido derecho a la «individualidad religiosa», carecía de concreción e identidad propia suficiente como para ser amparado como derecho fundamental. Más

31 NAKANO, T., NAKAMURA, M., TAKAHASHI, K. y TAKAMI, K. Kenpô I, op.cit., p. 309.

32 ÔISHI, M. y ÔZAWA, H. (coord.) Kenpô hanrei 憲法判例 (Jurisprudencia constitucional), Yûhikaku, Tokio, 2009, p. 135.

33 Sentencia de la Corte Suprema 63.6.1, repertorio de jurisprudencia civil vol. $42, \mathrm{n} .^{\circ}$, p. 270. 
bien al contrario, era la propia demandante quien debía mostrarse tolerante hacia dicho homenaje que además contaba con el beneplácito del difunto ${ }^{34}$.

En segundo lugar nos referiremos al derecho de los padres a proporcionar a sus hijos educación religiosa. La Constitución guarda silencio sobre tal libertad educativa garantizada a los padres aunque la doctrina mayoritaria no tiene inconveniente en reconocer su garantía constitucional ${ }^{35}$. Sin embargo existe disenso a la hora de incardinar dicha libertad en algún artículo concreto de la parte dogmática. Un sector mayoritario de la doctrina considera que este derecho de los padres, incluido dentro de una genérica libertad de enseñanza, debe configurarse como «derecho fundamental nuevo» (atarashii kibontekijinken 新しい基本的人権) y ser deducido de la cláusula general de derechos fundamentales del artículo $13^{36}$. Otros autores sin embargo, prefieren derivar la citada libertad directamente desde propio artículo $20^{37}$. La discusión, en principio teórica, tiene consecuencias prácticas que han de ser tenidas en cuenta. Pues, si entendemos que este derecho de educación religiosa se deriva del propio el artículo 20, una violación del mismo legitimaría a los padres para recurrir judicialmente alegando la vulneración de su propia propia libertad religiosa. Si por el contrario no decantamos por el artículo 13, su reparación en vía jurisdic-

${ }^{34}$ Esta sentencia ha sido objeto de profunda crítica, señalándose que lo que hace es obligar a la tolerancia de las minorías hacia las creencias de la mayoría y no al contrario. Un comentario de la misma podemos encontrarlo en AKASAKA, M. «Shinkyô no jiyû, seikyôbunri to jieikan no gôshi» 信教の自由、政教分離と自衛官の合祀 (Libertad religiosa, principio de separación Estado-religión y el funeral de un oficial de las Fuerzas de Autodefensa). En TAKAHASHI, K. (coord.), Kenpô hanrei hyakusen (daigohan) 憲法判例百選（第5版） (Cien sentencias constitucionales seleccionadas, 5. ed.), Yûhikaku, Tokio, 2007, pp. 98-99.

35 De hecho las libertades educativas de los padres no aparecen reconocidas, siquiera de manera general, dentro del catálogo de derechos fundamentales. El artículo 26 reconoce el derecho a recibir educación, pero como un derecho de naturaleza prestacional y no un derecho libertad. Sobre la naturaleza de la libertades educativas de los padres, véase por todos el excepcional estudio monográfico YONEZAWA, K. Kodomo, kazoku, kenpô 子供・家族・憲法 (Hijos, familia y constitución), Yûhikaku, Tokio, 1992.

36 Así, TAKENAKA, I. «Oyano kodomo wo kyôikusuru jiyû to kenpôjô no jikoketteiken» 親の子供を教育する自由と憲法上の自己決定権 (La libertad de los padres de educar a sus hijos y el derecho constitucional de autodeterminación) en Kobe University Educational Review, n. ${ }^{\circ} 44,1989$, p. 6. También UCHINO, M. «Kyôkiku no jiyû hôri no saikentô» 教育の自由法 理の再検討 (Repensando las libertades educativas) en Jurist, n. ${ }^{\circ} 884,1987$, p. 240, y URABE. N. Kenpô kyôshitsuI 憲法教室I (Aula de Derecho constitucional), Nihonhyôronsha, Tokio, 1988, p. 235.

37 KIMURA, T. Shinkyô no jiyû 信教の自由 (La libertad religiosa) en TAKAHASHI, K. (coord.), Kenpô no sôten 憲法の争点 (Problemática de Derecho constitucional), Yûhikaku, Tokio, 1999 , p. 88. 
cional quedaría supeditada a su reconocimiento previo como tal derecho fundamental con identidad propia ${ }^{38}$.

\subsubsection{Los límites de la libertad religiosa}

La libertad religiosa tiene un ámbito de proyección ad extra que, desde luego, resulta limitado por la protección de los derechos fundamentales de terceros y por el orden público. Ahora bien, los límites concretos a los que libertad religiosa queda sujeta deben ser a priori por determinados por el legislador, y a posteriori por jueces y tribunales en el ejercicio de sus funciones jurisdiccionales. Pues a diferencia de lo que ocurría con la Constitución Meiji, el legislador no tiene carta de blanca para regular el contenido de los derechos fundamentales y en ese sentido, cualquier restricción de la libertad religiosa ha de someterse a un riguroso control de constitucionalidad. Al igual que ocurre con el resto de derechos fundamentales, en el Derecho japonés, la concreta limitación de la libertad religiosa constituye un auténtico case law ${ }^{39}$. A continuación, haremos referencia a cuatro conocidas sentencias sobre esta materia:

1. Sentencia de la Corte Suprema de 15 de mayo de $1963^{40}$ :

En la sentencia se enjuiciaba un presunto delito de lesiones con resultado de muerte (artículo 205 del Código penal japonés) cometido por un monje budista al practicar un exorcismo mediante la quema de incienso, para sanar a una enferma mental que se suponía poseída por un espíritu maligno. La defensa alegaba que si bien la acción del monje era típica, su antijuridicidad quedaba excluida por haber sido realizada en el ejercicio de la libertad religiosa del monje (y con el consentimiento de los padres). El Supremo rechazó de plano esta argumenta-

38 Conviene tener en cuenta en este punto que los tribunales japoneses suelen mostrarse muy reticentes a reconocer nuevos derechos fundamentales vía artículo 13 .

$39 \mathrm{El}$ art. 98 de la Constitución proclama la supremacía formal y material de la Norma Suprema, estableciendo que cualquier acto del los poderes públicos se encuentra sometido al control de la constitucionalidad. Este control se atribuye a la Corte Suprema y resto de tribunales (art. 81) en el ejercicio de su jurisdicción. El sistema japonés pues no prevé la existencia de un tribunal ad hoc para el control previo sino que establece un modelo jurisdicción difusa de evidente influencia norteamericana.

40 Sentencia de la Corte Suprema 38.5.15, repertorio de jurisprudencia penal, vol. 17, n. ${ }^{\circ} 4$, p. 302. Un comentario a esta sentencia lo podemos encontrar en KOIZUMI, Y. "Shinkyô no jiyû to kajikito chiryô» 信教の自由と加持祈䘠治療 (Libertad religiosa y cura por exorcismo). En TAKAHASHI, K. (coord.), Kenpô hanrei byakusen (daigoban) 憲法判例百選（第5版）(Cien sentencias constitucionales seleccionadas, 5. ${ }^{a}$ ed.), Yûhikaku, Tokio, 2007, pp. 84-85. 
ción indicando que en este caso se superaban los límites racionales de la libertad religiosa al suponer la acción un grave atentado contra la vida de un tercero.

2. Sentencia de los Juzgados Sumarios (kan'i saibansho 簡易裁判所) de la ciudad de Kôbe de 20 de febrero de $1975^{41}$ :

Se trata de un juicio sobre delito de encubrimiento de criminal (art. 103 Código penal japonés) presuntamente cometido por un pastor protestante que había dado cobijo su iglesia a dos jóvenes que huían de la policía, acusados de un delito de allanamiento de morada y tenencia de armas. El pastor dedicó todo este tiempo para convencer a los muchachos de que se entregaran a las autoridades, y estos así lo hicieron ocho días después. El juez, entendió que, si bien la libertad religiosa del pastor quedaba sujeta a las exigencias de orden público, concretado en este caso por la legalidad penal, la acción del pastor no podía considerarse como antijurídica. Así, en su opinión la acción del pastor podía considerarse «formalmente» típica, pero tanto el objetivo perseguido por la misma (hacer que los muchachos reflexionaran sobre sus actos) y el resultado de la misma (la efectiva autoentrega de los fugitivos), no solo no ponía en peligro el orden público sino que, al contrario, promovía su defensa.

3. Sentencia del Tribunal Regional (chibôsaibansho 地方裁判所) de Tokio de 20 de marzo de $1986^{42}$ :

Estamos ante un curioso caso en el que unos padres de creencias cristianas reclamaban una presunta vulneración de su libertad religiosa por una escuela pública, pues los había registrados como «ausentes» en una lista de control de asistencia para una jornada de puertas abiertas (jugyô sankan 授業参観) ${ }^{43}$. El

${ }^{41}$ Sentencia del los Juzgados Sumarios de Kobe 50.2.20., en Hanrei Times, n. ${ }^{\circ} 318$, p. 219. Un comentario a esta sentencia lo podemos encontrar en KASUYA, T. «Bokkai katsudô no jiyû to hanninzôtokuzai» 牧会活動の自由と犯人蔵匿罪 (Libertad pastoral y delitos de encubrimiento de criminales). En TAKAHASHI, K. (coord.), Kenpô hanrei hyakusen (daigoban) 憲法判例 百選（第5版） (Cien sentencias constitucionales seleccionadas, 5. ed.), Yûhikaku, Tokio, 2007, pp. 88-89

42 Sentencia del Tribunal Superior de Tokio 61.3.20. repertorio de jurisprudencia administrativa vol.37, n. ${ }^{\circ}$ 3, p. 347. Un comentario a esta sentencia lo podemos encontrar en SAKATA, T. «Shûkyôtekiriyû niyoru gakkôjugyôkesseki no jiyû» 宗教的理由による学校授業欠席の自由 (La libertad de ausentarse de la escuela por razones religiosas). En TAKAHASHI, K. (coord.), Kenpô hanrei byakusen (daigohan) 憲法判例百選（第5版） (Cien sentencias constitucionales seleccionadas, 5. ${ }^{a}$ ed.), Yûhikaku, Tokio, 2007, pp. 92-93.

43 Este tipo de actividades es muy corriente en la escuela japonesa, siendo la mayoría de los padres muy participativos en las mismas. 
evento se venía realizando en domingo una vez al año. Pues bien, los demandantes argumentaban que era su derecho y el de sus hijos acudir a misa el domingo y que no existía deber alguno de participar en dicha jornada. Por ello exigían de la escuela una rectificación en la lista de control y una indemnización por daños morales. El tribunal rechazó todas las pretensiones de los padres destacando, en primer lugar, la especial importancia educativa de este tipo de actividades. Además correspondía al director del centro fijar una fecha concreta para su realización, por lo que tratar de acomodar el calendario escolar a todas y cada una de las preferencias religiosas de padres y alumnos haría imposible fijar ningún tipo de fecha. Por otro lado, la nota de ausencia en la lista de control no suponía ningún tipo de sanción, por lo que el perjuicio de los padres no podía demostrarse.

4. Sentencia de la Corte Suprema de 8 de marzo de $1998^{44}$ :

El asunto versaba sobre un estudiante de una escuela técnica pública (educación no obligatoria) de la ciudad de Kôbe, que era testigo de Jehová y que tuvo que hacer frente a dos medidas disciplinarias (repetición de curso y finalmente expulsión) al negarse a recibir clases de esgrima japonesa (kendô 剣道), obligatorias en dicha escuela, por considerarlas contrarias a sus creencias. El joven, que tenía un magnífico expediente académico, había solicitado varias veces la posibilidad de cursar alguna disciplina alternativa poder obtener los créditos equivalentes, pero se encontró siempre con la negativa del director. La escuela argumentaba que si aceptaba las peticiones del alumno estaría vulnerando el principio de separación.

El Alto Tribunal fallará en contra de la escuela, considerando que el director del centro se había extralimitado en el uso de sus facultades discrecionales, pues había puesto al alumno en el dilema de tener que actuar en contra de sus más sinceras creencias religiosas si quería obtener los créditos suficientes para poder graduarse. Entendió así el tribunal que en caso de conflicto entre el principio de separación en la escuela pública y la libertad religiosa de los alumnos, aquel debería de ceder ante ésta, pues la razón de ser de este principio es la propia garantía de la libertad religiosa.

${ }^{44}$ Sentencia de la Corte Suprema 8.3.8, repertorio de jurisprudencia civil vol. 50, n. ${ }^{\circ}$, p. 469. Un comentario a esta sentencia lo podemos encontrar en TSUCHIYA, H. «Shûkyôjô no riyû ni motozuku kendô no fujukô» 宗教上の理由に基づく剣道の不受講 (La renuncia por razones religiosas a tomar clases de esgrima). En TAKAHASHI, K. (coord.), Kenpô hanrei hyakusen (daigohan) 憲法判例百選（第5版） (Cien sentencias constitucionales seleccionadas, 5. ${ }^{a}$ ed.), Yûhikaku, Tokio, 2007, pp. 94-95. 


\subsection{El principio de separación religión-estado}

Junto con la ya analizada la libertad religiosa, el artículo 20 refuerza la garantía de este derecho fundamental con la adopción del principio de separación religión-estado. Dicho principio nace como respuesta y reflexión histórica a más sesenta años de Sintoísmo de Estado. Las cuestiones acerca de la naturaleza y el contenido constituyen uno de los puntos calientes del constitucionalismo japonés moderno.

\subsubsection{Naturaleza jurídica del principio de laicidad}

El debate acerca de la naturaleza jurídica del principio de laicidad puede resumirse en tres distintas posturas adoptas por doctrina y jurisprudencia. Aunque contenido del debate es principalmente teórico, las implicaciones prácticas son de importancia capital, pues según la postura adoptada el mecanismo judicial para la garantía del principio variará sustancialmente.

1. Principio de laicidad como garantía institucional:

Esta postura, de clara influencia alemana, es la que tradicionalmente ha venido apoyando la doctrina mayoritaria ${ }^{45}$. Según la misma, el principio de laicidad es una garantía institucional reconocida por la Constitución, al igual que lo serían también la autonomía universitaria (art. 23), la garantía de la propiedad privada (art. 29) y la autonomía local (art. 92). Siguiendo la teoría clásica de las garantías institucionales, mediante la adopción de este tipo de principios la constitución pretende asegurar que el legislador no elimine una institución o la pervierta ${ }^{46}$. La «institución» en el artículo 20 sería la separación entre el Estado y las confesiones religiosas.

Esta línea de pensamiento determina que ser el destinatario del principio de laicidad los poderes públicos, ante una contravención del mismo la única vía judicial abierta a los ciudadanos para reclamar sería a través de un procedimiento en interés público regulado en la Ley de Autonomía Local art. 242 bis deno-

45 Así TONAMI, K. «Seikyôbunri no hôtekiseikaku» 政教分離の法的性格 (Naturaleza jurídica del principio de separación religión-Estado). En Ashibe Nobuyoshi sensei kanrekikinen 芦部 信義先生還暦記念 (Estudios en homenaje del profesor Nobuyoshi Ashibe), Yûhikaku, Tokio, 1985. p. 555.

46 AKASAKA, M. «Jinken to seidohoshôron»人権と制度保障論 (Derechos fundamentales y garantías institucionales). En TAKAHASHI, K. (coord.), Kenpô no sôten 憲法の争点 (Problemática de Derecho constitucional), Yûhikaku, Tokio, 1999, p. 60. 
minado «litigio ciudadano» (jûmin soshô住民訴訟) y destinado a perseguir todas aquellas actuaciones de la administración local contrarias a Derecho ${ }^{47}$.

2. Principio de separación como derecho fundamental:

Esta postura interpreta el principio de separación como parte del contenido de la propia libertad religiosa, criticando la postura anterior en dos aspectos ${ }^{48}$. En primer lugar aduciendo que si entendemos la separación como una garantía institucional independiente del derecho fundamental de libertad religiosa, en el caso de que separación y libertad resultaren confrontadas, podría ocurrir que la defensa de aquella terminara en detrimento de ésta. En segundo lugar, se critica la insuficiencia práctica de la figura procesal del litigio ciudadano para corregir las posibles vulneraciones del principio de separación perpetradas por la administración de Estado, pues este tipo de litigo solo permite dirigirse contra la administración local. Es por ello que si entendemos la separación como parte integrante de la propia libertad religiosa, ante vulneraciones de dicho principio por parte de cualquier administración pública, todos los ciudadanos estarían legitimados activamente para incoar un procedimiento de reparación en sede judicial, cómo directamente afectados por la actuación de los poderes públicos.

3. Principio de separación como garantía de la libertad religiosa:

La tesis del principio de separación como garantía de la libertad religiosa nace como síntesis de las bondades de las dos posiciones doctrinales anteriormente referidas, y, sobre todo, para superar sus defectos ${ }^{49}$. En primer lugar, se critica la teoría de la garantía institucional aduciendo que lo pretendido por el principio de separación no es la institucionalización de la separación religiónestado, sino prohibir que las relaciones entre el Estado y una confesión religiosa resulten institucionalizadas (como ocurrió con el Sintoísmo de Estado). La finalidad de prohibición es la plena garantía de la libertad religiosa y, en este sentido, el principio de separación actúa de manera análoga al binomio free exercise

47 Este tipo de procedimiento administrativo se encuadra dentro de una categoría «procedimientos objetivos» (kyakkan shoshô 客観訴訟), de interés público, en los que para su legitimación activa no se requiere de la existencia de vulneración de derechos subjetivos particulares.

48 Así, URABE, N. «Seikyôbunrikitei no seikaku» 政教分離規定の性区 (La naturaleza de la clausula de separación Estado-religión). UNIVERSIDAD DE SENSHÛ, Takayanagi Nobuichi sensei kokikinen ronbunsh $\hat{u}$ 高柳信一先生古希記念論文集 (Estudios en homenaje del profesor Nobuichi Takayanagi), Senshû University, Chiba, 1992, p. 55.

49 Así, ÔISHI, M., Kenpô kôgi II, op.cit., p. 125. 
clause-stablishment clause recogido por la Primera Enmienda de la Constitución norteamericana.

A continuación se critica la segunda tesis del principio de separación como derecho fundamental desde dos frentes. En primer lugar señala el sujeto del principio de separación establecido por la Norma Fundamental son los poderes públicos (Cfr. arts. 20.1 párrafo segundo, 20.3 y 89). Es incorrecto por tanto entender dicho principio como parte integrante del derecho de libertad religiosa, cuyo destinatario son los individuos. En segundo lugar se critica el que dicha tesis legitime a cualquier ciudadano, independientemente de que sus derechos subjetivos se hayan visto efectivamente vulnerados, para reclamar ante los tribunales el control de la constitucionalidad de una determinada actuación de los poderes públicos. Pues caso contrario, el número de posibles litigios sería interminable. Según esta teoría de principio de separación como garantía, que las únicas vías para atacar actuaciones de los poderes públicos que contravengan dicho principio de separación serán dos: 1. la del litigio ciudadano, contra la administración local, y, 2. la de un procedimiento ordinario contra la administración, ya sea local o estatal, siempre y cuando el particular pruebe la concreta vulneración de sus derechos.

\subsubsection{Casuística constitucional sobre los límites del principio de separación}

Principio de separación, no quiere decir «aislar» completamente a la religión de la esfera pública. Si dejamos el hecho religioso completamente incomunicado de la actuación de los poderes públicos el resultado que obtendremos será contraproducente para la propia libertad religiosa, razón de ser de este principio. Una prohibición radical de que los poderes públicos mantengan cualquier tipo de relación e interacción con las diferentes comunidades religiosas, hasta el punto de ignorarlas completamente, redundará en un trato discriminatorio de la religión, contraviniendo de este modo el principio de igualdad establecido por la propia Constitución en su artículo $14^{50}$.

Así, tanto doctrina como jurisprudencia reconocen la necesidad de que exista un cierto nivel de relación entre el Estado y las diferentes confesiones presentes en la sociedad; la cuestión reside, entonces, en dilucidar los límites de lo constitucionalmente permitido. En este punto, la opinión doctrinal se divide entre aquellos autores que defienden una separación estricta y aquellos que creen

${ }^{50}$ En este sentido vid. UEDA, M., «Shinkyô no jiyû no hoshô» 信教の自由の保障 (La garantía de la libertad religiosa) en Ryĥkkoku University Law Review, vol. 14, n. ${ }^{\circ}$ 4, 1982, p. 61. 
deseable una separación más laxa ${ }^{51}$. Sea como fuere, debe quedar claro que todos los autores coinciden en que el mandato constitucional es el de separación y que la relación (sea esta más o menos amplia) es la excepción a dicha regla. En otras palabras, la Constitución japonesa no establece ningún principio de cooperación religión-estado. En este sentido, no sería correcto interpretar este principio de separación como equivalente al de aconfesionalidad que establece la Constitución española ${ }^{52}$.

Pues bien, para determinar el nivel de relación permitido entre Estado y confesiones, o lo que es lo mismo, determinar si una actuación concreta de los poderes públicos es contraria al principio de separación, doctrina y jurisprudencia se han venido sirviendo de un conocido recurso de la jurisprudencia de la Corte Suprema de los Estados Unidos: el Lemon test ${ }^{53}$. Dicho test consiste en una serie de tres criterios cumulativos para enjuiciar la actuación de los poderes públicos en relación con el principio de separación: «objetivo secular» (secular purpose), «efecto primordial» (primary effect), y «confusión excesiva» (excesive entanglement).

La primera vez que la Corte Suprema japonesa utilizó criterios análogos a aquellos del Lemon test, fue en su arquetípica sentencia de 13 de julio de $1973^{54}$. El fallo resolvía un litigio ciudadano contra la actuación del ayuntamiento de la

${ }^{51}$ Entre los que abogan por una separación estricta véase por todos ASHIBE, N., Kenpôgaku III. Jinken kakuron (I) 憲法学III人権各論I (Ciencia del Derecho constitucional. Teoría general de los Derechos Fundamentales I), Yûhikaku, Tokio, 1998, pp. 181-182. Esta opinión puede considerarse mayoritaria en la actualidad. Con respecto a los autores que abogan por una separación más laxa, véase por todos MOMOCHI, A., Kenpô to seikyôbunri no gensoku 憲法と政教分離の原 則 (Constitución y principio de separación Estado-religión), Seibundô, Tokio, 1991, p. 61.

52 Cfr. art. 16.3 de la Constitución española. Nuestra Norma Fundamental, establece un deber de cooperación por parte de los poderes públicas con las confesiones religiosas presentes en la sociedad española. Fruto de dicho mandato constitucional son los acuerdos de cooperación firmados entre el estado español y la Santa Sede, y entre el estado español y ciertas confesiones de «notorio arraigo» (en términos de la propia LORL). Pues bien, desde el prisma de la Constitución japonesa, un sistema similar al español no tendría cabida dentro de su marco constitucional, y así es como parece interpretar ASHIBE, N. en su obra Shûkyô Jinken Kenpôgaku 宗教・人権・憲法学 (Religión, Derechos Humanos y Ciencia constitucional) Yûhikaku, Tokio, 1999, pp.10-12, cuando se refiere al caso italiano (ciertamente cercano al español).

${ }^{53}$ Lemon v. Kurtzman. 403 U. S. 602 (1971).

54 Sentencia de la Corte Suprema 52.7.13, repertorio de jurisprudencia civil, vol.31, n. ${ }^{\circ} 4$, p. 533. Un comentario a esta sentencia lo podemos encontrar en HIBINO, T., «Shintôshiki jichinsai to seikyôbunri no gensoku» 神道式地鎮祭と政教分離の原則 (El ritual sintoísta de purificación de la tierra y el principio de separación Estado-religión). En TAKAHASHI, K. (coord.), Kenpô hanrei byakusen (daigohan) 憲法判例百選（第5版） (Cien sentencias constitucionales seleccionadas, 5. ed.), Yûhikaku, Tokio, 2007, pp. 96-97. 
ciudad de Tsu, en la prefectura de Mie que, con ocasión de la construcción de un polideportivo público, había financiado una serie de ceremonias sintoístas para purificación del terreno (jichinsai 地鎮祭).

En primera instancia se había fallado a favor de la parte demandada aduciendo que este tipo de rituales sintoístas estaban tan secularizados en la sociedad japonesa que no podían considerarse como una verdadera actividad religiosa. Sin embargo, el Tribunal regional de Nagoya en segunda instancia, cambió completamente el sentido de la sentencia, aportando tres criterios objetivos para catalogar si un acto debiera ser considerado «religioso»; a saber: que el acto esté presidido por un ministro religioso, que se desarrolle siguiendo una liturgia determinada, y que no pueda predicarse del mismo un grado de secularización suficiente ${ }^{55}$. Aplicados estos criterios al ritual sintoísta en cuestión, se determinó que la actuación del ayuntamiento de Tsu era inconstitucional.

La sentencia será recurrida ante el Supremo que volverá a torcer el argumento, declarando finalmente la constitucionalidad del acto. Según el Alto Tribunal, para determinar la adecuación de una actuación de los poderes públicos al principio de separación, deben de realizarse dos indagaciones. Primero, ver si la actuación persigue un objetivo religioso, y segundo, comprobar si su resultado es la ayuda, apoyo y promoción, o bien la represión de una cierta confesión religiosa. Como el ritual sintoísta de purificación de la tierra no perseguía ningún objetivo religioso, ni a la postre suponía ningún tipo de ayuda, apoyo o promoción de la religión sintoísta, no podía ser considerado como prohibido por el art. 20.3 de la Constitución.

Los criterios propuestos por el Supremo en la citada sentencia reciben comúnmente el nombre de «test objetivo-resultado» (mokuteki kôka kijun 目的 効果基準) y, obviamente, son una adaptación al constitucionalismo japonés del Lemon test norteamericano. Aunque en puridad, lo que hace la Corte Suprema japonesa es tomar los dos primeros criterios del citado test obviando el de confusión excesiva. Es por ello que se acuse a la postura del Supremo de permitir una relajación en el principio de separación ${ }^{56}$.

Sea como fuere, lo cierto es que el «test objetivo-resultado» ha hecho fortuna en la jurisprudencia constitucional japonesa, llegando a ser sistematizado en todos los litigios en los que el principio de separación se ha visto involucrado.

${ }^{55}$ Sobre la sentencia del Tribunal Superior de Nagoya Vid. nota n. ${ }^{\circ} 26$.

56 Así, SAKAMOTO, M. Kenpôriron II 憲法理論II (Teoría del derecho constitucional II), Seibundô, Tokio, 1994, p. 355. También KOBAYASHI, T., «Seikyôbunri ihan no shinsakijun nikansuru kaishakurontekioboegaki» 政教分離違反の審査基準に関する解釈論的覚書 (Notas sobre la interpretación de los criterios para analizar las infracciones del principio de separación Estado-religión) en Nanzan University Law Review, vol. 12, n. ${ }^{\circ} 4$, 1989, pp. 20-21. 
Así ocurrió por ejemplo en la sentencia de la Corte Suprema de 16 de febrero de $1993^{57}$. Se trata éste de un litigio en el que se discutía la constitucionalidad de la cesión de uso de unos terrenos públicos por parte del ayuntamiento de la ciudad de Minoo, en la prefectura de Osaka, a una asociación de familiares de caídos en la guerra, para el traslado de un monumento funerario anteriormente sito en una escuela pública de la ciudad. Tras aplicar el «test objetivo-resultado» al tribunal a quo declaró inconstitucional el acto, argumentando que el monumento funerario debía ser considerado como «instalación de carácter religioso» y que la asociación de familiares debía ser considerada como una comunidad religiosa.

La sentencia será recurrida y tanto el tribunal de apelación como la Corte Suprema fallarán de manera diametralmente opuesta. En primer lugar, se determinó que dicho monumento funerario era una instalación para la memoria de los fallecidos en la guerra y que por tanto su carácter religioso era extremadamente tenue. En segundo lugar, concluyó que la asociación de familiares, constituida para honrar la memoria de los difuntos, nada tenía que ver con una confesión religiosa. Con respecto al objetivo del traslado del monumento funerario, se determinó que era claramente secular. Así, en esta sentencia el Supremo se sirvió del «test objetivo-resultado» para justificar la constitucionalidad del acto más que para fiscalizarlo.

La tendencia conservadora en la jurisprudencia constitucional de la Corte Suprema experimentó un cambio de sentido a partir de la segunda mitad de la década de los noventa, tras su sentencia del Supremo de 2 de abril de $1997^{58}$. Se trataba de un litigio ciudadano acerca de la constitucionalidad de una serie de pagos efectuados por el presidente electo de la prefectura de Ehime, desde 1981 a 1986, para sufragar los gastos unas de ofrendas al santuario sintoísta de Yasukuni sito en dicha prefectura ${ }^{59}$. Pues bien, el tribunal de primera instancia

57 Sentencia de la Corte Suprema 5.2.16, repertorio de jurisprudencia civil, vol. 47, n. $^{\circ} 3$, p. 1687. Un comentario a esta sentencia lo podemos encontrar en UZAKI, T., «Chûkonhi, ireisai to seikyôbunri no gensoku» 忠魂碑慰霊祭と政教分離の原則 (Monumento funerario en memoria de los caídos y principio separación Estado-religión). En TAKAHASHI, K. (coord.), Kenpô hanrei hyakusen (daigohan) 憲法判例百選（第5版） (Cien sentencias constitucionales seleccionadas, 5. ${ }^{\mathrm{a}}$ ed.), Yûhikaku, Tokio, 2007, pp. 106-107.

58 Sentencia de la Corte Suprema 9.4.2, repertorio de jurisprudencia civil, vol. 51, n. ${ }^{\circ}$, p. 1673. Un comentario a esta sentencia lo podemos encontrar en TOMATSU, H., «Tamagushiryô toshiteno kôkinshishutsu to seikyôbunri no gensoku»玉ぐし料としての公金支出と政教分 離の原則 (Pago de ofrendas sintoístas con dinero público y principio de separación Estado-religión). En TAKAHASHI, K. (coord.), Kenpô hanrei hyakusen (daigoban) 憲法判例百選（第5版）

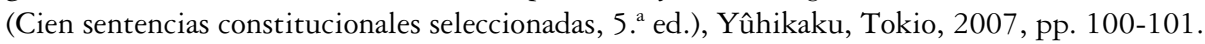

59 Yasukuni es el nombre de un santuario sito en Tokio pero con sedes locales en todas las prefecturas del país. Está consagrado a la protección de la Nación y dedicado a todos los comba- 
aplicará «test objetivo-resultado» determinando la inconstitucionalidad de la actuación del presidente de la prefectura, por perseguir ésta un objetivo religioso y promocionar la religión sintoísta. El fallo será impugnado y el tribunal ad quem revertirá la sentencia, argumentando que aunque el acto tenía un carácter religioso, dado el escaso importe de las ofrendas ( $\tan$ solo 31.000 yenes aproximadamente) el acto podría considerarse como secular. La sentencia será finalmente recurrida al Supremo que, apoyando la tesis del tribunal a quo, finalmente declarará la inconstitucionalidad del acto impugnado.

Recientemente la Corte Suprema, en su sentencia 20 de enero de 2010, ha vuelto a declarar inconstitucional una actuación de los poderes públicos ${ }^{60}$. La sentencia resuelve un litigio ciudadano sobre un caso de cesión de uso gratuita de terrenos públicos a dos santuarios sintoístas en la prefectura de Hokkaidô: el de Tomihira y el de Sorachibuto. Estos santuarios se encuentran sitos en terrenos pertenecientes a la ciudad de Sunagawa desde antes del advenimiento de la Constitución de 1947. La sentencia declaró que en ambos casos se daba una situación de inconstitucionalidad sobrevenida que debía considerarse «disuelta» (kaishôo解消), ya que la cesión gratuita de terreno era en realidad la continuación de una situación fáctica anterior a la Constitución. Ahora bien, esto para el caso del santuario de Tomihira. Con respecto al santuario de Sorachibuto, la situación de inconstitucionalidad seguía presente (o mejor dicho volvía a aflorar) ya que en el terreno de dicho santuario se habían edificado con posterioridad a 1947 un torii (鳥居, especie de portalón ceremonial) y una hokora (祠, pequeña capilla sintoísta). En el caso de Sorachibuto, la cesión gratuita del terreno beneficiaba a una confesión religiosa, ya que el santuario había echo uso de un terreno público para edificar parte de sus instalaciones, y en este sentido la cesión resultaba contraria al principio de separación.

tientes fallecidos en las guerras en las que participó Japón tras la Restauración Meiji. Siendo pieza clave en el armazón del Sintoísmo de Estado y de innegable espíritu nacionalista (entre los venerados hay varios criminales de guerra), el santuario de Yasukuni se encuentra envuelto en permanente polémica, entre otras cosas por las visitas que un buen número de primeros ministros desde 1985 han venido realizando con motivo de la conmemoración del final de la guerra del Pacífico. Una monografía dedicada exclusivamente al santuario y su problemática constitucional podemos encontrarla en MOMOCHI, A., Yasukuni to kenpố 靖国と憲法 (Yasukuni y la Constitución), Seibundô, Tokio, 2003.

${ }^{60}$ Sentencia de la Corte Suprema 22.1.20, repertorio de jurisprudencia civil, vol. 64, n. ${ }^{\circ} 1$, p. 1. Un comentario a esta sentencia lo podemos encontrar en ISHIDA, A. «Hokkaidô sunagawashi, sorachibutojinja seikyôbunrijunminsoshô» 北海道砂川市空知太字神社政教分離住民訴訟 (El litigio ciudadano por infracción del principio de separación Estado-religión, contra el santuario de Sorachibuto en la ciudad de Sunagawa, Hokkaidô) en Hôgaku Seminar, n. ${ }^{\circ}$ 673, 2011, pp. 30-33. El autor de este artículo fue el abogado de la parte demandante en la causa. 
El fallo resulta especialmente interesante porque el Alto Tribunal vuelve a mencionar el «test objetivo-resultado» pero esta vez para descartar su uso en el enjuiciamiento del acto. A diferencia de la casuística anterior, lo que aquí se estaba enjuiciando era una situación continuada y no un acto concreto de la Administración. En otras palabras, el contenido del fallo consistía en determinar si un hecho bastante común en Japón (esto es, que un santuario sintoísta se encuentre efectivamente situado en terreno público) debía o no ser declarado inconstitucional, y en opinión de la Corte Suprema, el «test objetivo-resultado» no resultaba adecuado para ello, por no tratarse en este caso de actuaciones de los poderes públicos de naturaleza puntual.

\section{A MODO DE CONCLUSIÓN}

Tal y como se puede desprender de nuestra exposición, el ordenamiento jurídico nipón garantiza la libertad de creencias de una manera óptima, acorde con los estándares de un estado de Derecho moderno. La Constitución sistematiza a lo largo de su articulado la protección de esta libertad, estableciendo un mecanismo de revisión judicial para salvaguardarla de cualquier vulneración por parte de los poderes públicos. Tras décadas de existencia de una religión de Estado, con el consiguiente menoscabo de las libertades ciudadanas, el sistema corrigió sus deficiencias mediante la adopción de principios tales como el de igualdad, no discriminación y el de separación.

En realidad, Japón presenta un alto grado de estabilidad social en todo lo concerniente a cuestiones de naturaleza ideológica y sobre todo religiosa ${ }^{61}$; aunque en nuestra opinión esta paz social se deba más que a las bondades del sistema, a razones de índole sociológico cultural, ya que es la japonesa una sociedad extraordinariamente homogénea, en el que las creencias personales suelen relegarse al ámbito más íntimo y reservado. Como dice un famoso proverbio japonés, «la estaca que sobresale se lleva un mazazo»(deru kui ga utareru 出る杭が打たれる): gustan pues los nipones de rehuir del conflicto y es evidente que las diferencias

${ }^{61} \mathrm{Si}$ bien es cierto que en años recientes se han producido incidentes de trasfondo religioso que han hecho cuestionar el sistema. Difíciles de borrar de la memoria colectiva permanecen los ataques terroristas perpetrados por miembros de culto Aum Shinrikyô (オーム真理教). Aum Shinrikyô fue el nombre de un movimiento religioso japonés que en marzo de 1995 perpetró una serie de ataques con gas sarín en el metro de Tokio, provocando numerosas víctimas mortales y heridos. La Corte Suprema ordenó la disolución del culto en su auto de 1 de enero 1996. Vid. auto de la Corte Suprema 8.1.30., repertorio de jurisprudencia civil, vol. 50, n. ${ }^{\circ} 1$, p. 199. En la actualidad el grupo ha cambiado su nombre por el de Aleph y sigue contando con numerosos adeptos. 
ideológicas y religiosas pueden menoscabar el ideal de armonía social reinante en el país ${ }^{62}$.

Entonces, ¿qué ocurriría si la sociedad japonesa pierde la homogeneidad de la que hace gala? ¿Se rompería este estado de armonía frente a un aumento de las minorías religiosas, provocado por unos índices de inmigración que, de hecho, están aumentando gradualmente? Nos resulta imposible aventurar una respuesta en uno u otro sentido, pero obvia decir que el sistema deberá ser, al menos, replanteado. Pues a pesar de sus sólidos fundamentos (no en vano se elaboró tomado como modelo al norteamericano, cuya sociedad es paradigma del multiculturalismo), Japón apenas ha tenido que lidiar hasta el momento con auténticos problemas de índole religiosa y cultural. Creemos que Japón deberá entonces volver la mirada (de nuevo) a Occidente y sus naciones, donde el multiculturalismo es ya una realidad fáctica. Y quizá entonces el modelo español, con sus deficiencias, pueda ser de interés académico para la doctrina científica nipona $^{63}$.

\section{Title:}

\section{FREEDOM OF BELIEF IN THE JAPANESE CONSTITUTION}

\section{Resumen:}

La Constitución de Japón (1947) garantiza el derecho a la libertad de creencias, sistematizado a lo largo de su articulado. El sistema, influenciado notoriamente por la Constitución norteamericana, presenta notas características de la idiosincrasia japonesa que resultaran de interés para el lector occidental. En el presente trabajo se realiza un estudio sobre la garantía de esta libertad (tanto en su vertiente ideoló-

${ }^{62}$ Resulta sorprendente el relativamente escaso número de litigios en una sociedad como la japonesa, con población total de 127. 799.000 habitantes (en 2011, datos obtenidos en la página web de la Agencia Japonesa de Estadística http://www.stat.go.jp/data/jinsui/2011np/). El número de litigios presentados en cualquier instancia ante tribunales japoneses fue de 4.546 .332 en 2007, de 4.432 .984 en 2008, de 4.597.225 en 2009 , de 4.317 .905 en 2010 y de 4.059 .773 en 2011. Los datos son los publicados por el Ministerio de Justicia y pueden consultarse en http:// www.courts.go.jp/sihotokei/graph/pdf/B23No1-1.pdf (documento consultado en abril de 2013).

${ }^{63}$ Habida cuenta de los cambios que se están produciendo en la sociedad japonesa desde el año 2004, la Oficina de asuntos culturales (Bunkachồ文化庁) del Ministerio de educación y ciencia (Mombukagakushô 文部科学省), viene realizando un estudio de amplio espectro sobre las relaciones Estado-confesiones religiosas en diferentes estados europeos. El autor de estas páginas, junto al catedrático Jin KITAHARA (universidad de Surugadai) tuvo ocasión de participar en el estudio sobre el Estado español, con resultados acogidos con gran interés por parte de la burocracia nipona. Parte del trabajo realizado puede consultarse en: www.bunka.go.jp/shukyouhoujin/ pdf/h24kaigai.pdf (documento consultado en septiembre de 2012), pp. 136-185. 
gica como religiosa) a través del análisis de la evolución histórica del sistema, de la revisión de la doctrina científica más aplaudida y de la jurisprudencia más relevante sobre la materia.

\begin{abstract}
:
The Constitution of Japan (1947) guarantees the right to freedom of belief, which is systematized in several articles of the text. Having received a notorious influence from the U. S Constitution, the system shows some characteristic features that should be of interest to western scholars. In this work a study on this freedom (both on its ideological and religious sides) is carried out by analyzing the historical evolution of the system and by revising the most praised academic theories as well as the most relevant case law on this matter.
\end{abstract}

\title{
Palabras clave:
}

Constitución japonesa, libertad de creencias, Sintoísmo de Estado, libertad de conciencia, libertad religiosa, principio de separación Estado-religión

\section{Keywords:}

Japanese Constitution, freedom of belief, State Shinto, freedom of conscience, religious freedom, the principle of separation between State and Religion. 
